\title{
Research on Self-Adaptive Control Technology in Lockup Process of Automatic Transmission
}

\author{
Wentao Sun ${ }^{1, a^{*}}$, Yifan Tong ${ }^{1, b}$, Ying Liu ${ }^{1, c}$ \\ ${ }^{1}$ China Automotive Engineering Research Institute Co., Ltd. No.9 Jinyu Avenue, \\ New North Zone, Chongqing, China \\ asunwentao@caeri.com, btongyifan@caeri.com, ${ }^{\mathrm{C}}$ liuying@caeri.com
}

Keywords: Automotive transmission, Lockup process, Self-adoptive control

\begin{abstract}
In order to research the torque converter lockup process and improve the quality, the lockup process system of Electronic Automatic Transmission is analyzed. The lockup process is analyzed detailed and the rule of lockup process is gotten and at the same time the rule of clutch filltime/ramping off is researched. Research shows it can improve the quality of lockup process using the different control strategy in different phases. It is necessary to use the control strategy. Through a test, the process of the clutch fill-time/ramping off, open-loop and closed-loop of adaptive is researched. After using the control strategy, the lockup quality is improved.
\end{abstract}

\section{Introduction}

Nowadays, AT takes a significant share of electronic automatic transmissions. Since equipped with torque converter, it makes the AT in a unique position on ride comfort, and in order to enhance fuel economy, lockup clutch is added. Because it is possible that the clutch may be unlock before or after shifting, if the control is failed, the lockup impact will be so great that the life of the clutch may be shortened. There are lots of factors affecting the lockup process, and the author finds that the selfadoptive control technology is an effective controlling method. This paper mainly researches how to improve the quality of the lockup process.

\section{Theory Analysis}

First of all, modeling analysis for the torque converter lockup process [1]:

Mechanical model related to clutch

The quality of the lockup process is determined by the joint process of clutch, in which the rotating speeds of friction plate and driven friction plate become consistent. Fig. 1 illustrates the mechanical model related to clutch.

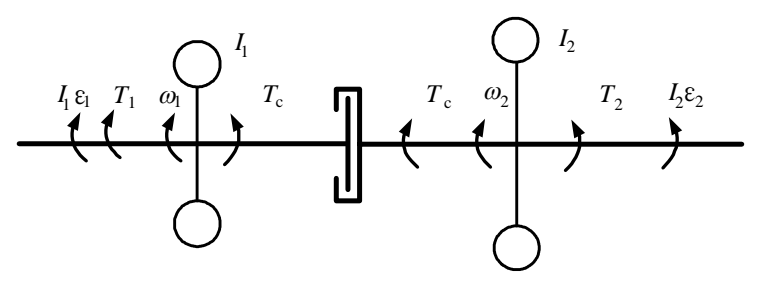

Fig. 1 Mechanical model of clutch.

$$
M_{c}=M_{z}-J_{z} \frac{d \omega_{z}}{d t}
$$




$$
M_{c}=M_{b}+J_{b} \frac{d \omega_{b}}{d t}
$$

In the above formula: $M_{z}$ : driving torque of driving friction plate, $N . m ; J_{z}$ : rotational inertia of driving friction plate, $\mathrm{kgm}^{2}$;

$\omega_{b}$ : angular velocity of driving friction plate, $\mathrm{rad} / \mathrm{s} ; M_{b}$ : driven torque of driving friction plate , $N . m J_{b}$ : rotational inertia of driving friction plate, $\mathrm{kgm}^{2} ; \omega_{b}$ : angular velocity of driving friction plate , $\mathrm{rad} / \mathrm{s}$.

For wet clutch, its jointing features should be firstly discussed from $\Delta \omega_{k}$, the speed difference between driving and driven friction plate :

$$
\Delta \omega_{k}=\frac{\omega_{T}}{i_{k 1}}-\omega_{O} i_{k 2} \quad k=1,2
$$

In the formula:

$\omega_{T}$ : turbine angular velocity, $\mathrm{rad} / \mathrm{s}$.

When $\Delta \omega_{k} \neq 0$, wet clutch is in the state of sliding-friction, and the torque of the clutch is:

$$
M_{C}=\operatorname{sign}\left(\Delta \omega_{k}\right) \mu_{c} p_{c} r_{c} z
$$

In the formula:

$M_{C}$ : friction torque, N.m; $\mu_{c}$ : friction coefficient; $p_{c}$ : clutch pressure, $p_{a} ; r_{c}$ : equivalent effect radius, $\mathrm{m} ; z$ : number of friction pairs

When $\Delta \omega_{k}=0$, wet clutch is in the state of complete jointing, the transmitting torque is:

$$
-\mu_{c 0} p_{c} r_{c} z \leq M_{C} \leq \mu_{c 0} p_{c} r_{c} z
$$

In the formula:

$\mu_{c 0}$ : clutch static friction coefficient.

Generally, the above analysis shows that the friction torque of a clutch is mainly determined by friction coefficient, clutch pressure, equivalent effect radius and the number of friction pairs, etc. Since the equivalent effect radius and number of friction pairs are constants, while the friction coefficient and the clutch pressure keep changing, the author finds that controlling the process of the clutch filltime/ramping off is a great strategy [2].

Mathematical model of torque converter

The model is established on the following assumptions:

The features of torque converter will not be widely varied between in transitional duty cycle and in static duty cycle;

In circuit, the rotating speed of fluid will not be slower than the speed of the working wheel;

Therefore, the output torque of converter shall be counted by the original characteristic of torque converter.

$$
\begin{aligned}
& \lambda_{P}=f\left(i_{y}\right) K=f\left(i_{y}\right): \\
& M_{p}=\rho g \lambda_{p} n_{p}^{2} D^{5} \\
& M_{t}=K M_{p}
\end{aligned}
$$

The friction torque of lockup clutch, $M_{m}$ : 
$\begin{cases}M_{m}=0 & x<\Delta \\ M_{m}=\mu_{d} P_{c o n} R z & x \geq \Delta\end{cases}$

In the formula:

$M_{t}:$ turbine torque, $M_{p}:$ pump wheel torque; $p_{c o n}$ : restoring force of lockup clutch friction plate; $\mu_{d}$ : dynamic friction coefficient of friction plate; $R, z:$ the average working radius of lockup clutch friction plate and the number of friction pairs.

$\Delta:$ actual maximum total interval of lockup clutch piston

$x$ : actual power stroke of lockup clutch piston

When the torque converter is completely locked, $M_{p}=M_{t}$, and $n_{p}=n_{t}$.

Mathematical model of lockup torque converter:

The work states of lockup torque converter can be divided into three classes, and the following are mathematical model of each statement:

unlocked status:

$\left(p-p_{b}<0 ; x<\Delta\right)$

$\dot{\omega}_{p}=\frac{M_{e b}-M_{p}}{I_{p}}$

$\dot{\omega}_{t}=\frac{M_{t}-M_{t 0}}{I_{t}}$

$M_{m}=0$

(1) lockup process:

$$
\left(p-p_{b} \geq 0 ; x \geq \Delta\right)
$$

$\dot{\omega}_{p}=\frac{M_{e b}-\left(M_{m}+M_{p}\right)}{I_{p}}$

$\dot{\omega}_{t}=\frac{\left(M_{m}+M_{t}\right)-M_{t 0}}{I_{t}}$

$M_{m}=\mu_{d} P_{c o n} R \cdot z$

(2) completely jointing:

$\left(p-p_{b}>0 ; p=p_{\max } ; x \geq \Delta\right)$

$\dot{\omega}_{t}=\dot{\omega}_{p}=\frac{M_{e b}-M_{t 0}}{I_{p}+I_{t}}$

$M_{m}=M_{p}=M_{t}$

\section{Controlling Strategy Analysis}

Control of Lockup Process. The quality of the lockup process dominantly depends on the oil filling order of clutch, which can be classified into the following 4 phases [3]:

1) At the beginning of the lockup, the clutch that is filling oil will receive a command to keep 
electromagnetism valve opening for a period of tome, and piston starts to move until the piston cavity is filled with oil, which makes the lockup clutch reach its start point of oil-filling pressure. During this period, the duty ratio of the electromagnetism valve driving signal reaches $100 \%$, which means it has been completely opened.

2) ECU open-loop controls the rising slope of the duty ratio of electromagnetism valve driving signal, therefore, it can control the rising speed of the pressure of lockup clutch, until the rotating speed of turbine declines to stop.

3) When it is detected that the engine speed is falling, ECU began to enter the closed-loop control of the lockup clutch. Closed-loop control is a positive controlling period through modulating the electromagnetism valve driving signal. This controlling process will continue till the rotating speed differences between driving and driven friction plate $s$ are disappeared. This will maintain an optimal engine speed curve.

4) When ECU detected that the engine speed is equal to the turbine speed (synchronization), the lockup clutch completely joint, and ECU will send the electromagnetism valve a command of "Open", so that the lockup clutch completely joint, and ultimately complete the lockup process [4].

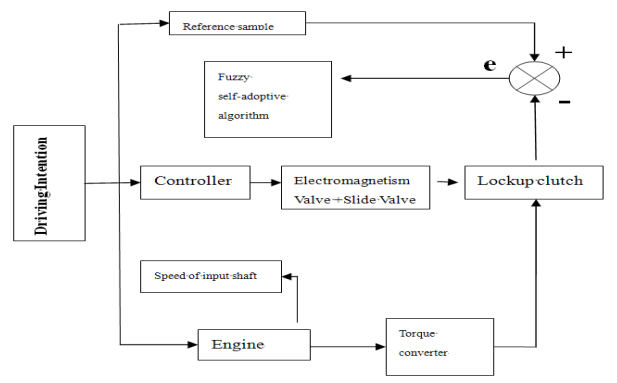

Fig. 2 Lockup process framework

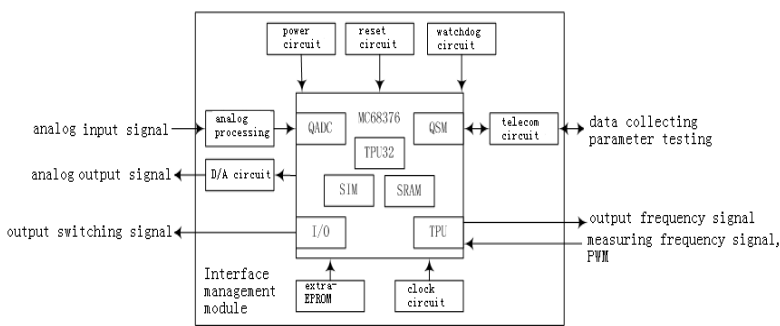

Fig. 3 Control system

The above analysis shows that the lockup process can be divided into three phases [5]: the phase of initial oil filling and ramping off, open circuit control stage and closed circuit control, and different stages require different control strategies. 1, the initial oil-filled stage: If the initial fill time is too long, the clutch will joint too fast, and cause serious torque disturbance; if too short, it will increase the lockup time. Because of manufacturing errors, the oil temperature, oil pressure and other parameters, Clutch fill time varied greatly. Therefore, it is necessary to apply self-adaptive control strategy. Firstly, set the initial fill time, and then according to feedback from pressure sensor, the oil fill time will modify automatically, the modified parameters will be saved in $E^{2}$ PROM. When the next lockup process begins, (for simultaneous monitoring of the external parameters such as oil temperature, oil pressure, etc.) the modified values will be applied. After several modifications, the value will be more and more accurate. 2, Open circuit control phase: it comes when the clutch is filled by oil but the transmission torque has not slowed down the engine speed. This phase modulates according to the oil pressure growth rates, which have been set in advance, till the engine speed is decreased. This phase is mainly affected by oil temperature, and can be corrected according to ideal reference sample. 3, closed circuit control phase: it is a typical non-linear and time-variant system. Since the system there is oil leakage, friction, mechanical inertia delay, electro-hydraulic response of electromagnetism valve and the nonlinear flow characteristics of hydraulic valve, this control system reflects a complex non-linear feature (see Fig. 2). The control parameters can adjust automatically depending on different operating conditions, which are shown in Fig. 3.

Control of Lockup Process. The ECU of electronic automatic transmission selected here is Motorola's 32-bit microcontroller MC68376, which is used as the core of integrated control system. The control system is shown in Fig. 4: 
The driver module completes the control on electromagnetism valve of lockup clutch, and PWM signal generated from TPU is regarded as controlling signal. Each channel of the module can be achieved high-resolution fixed frequency and duty ratio control without CPU intervention. Therefore, this module is fully qualified to meet the high requirement of digital pressure regulator of timing control.

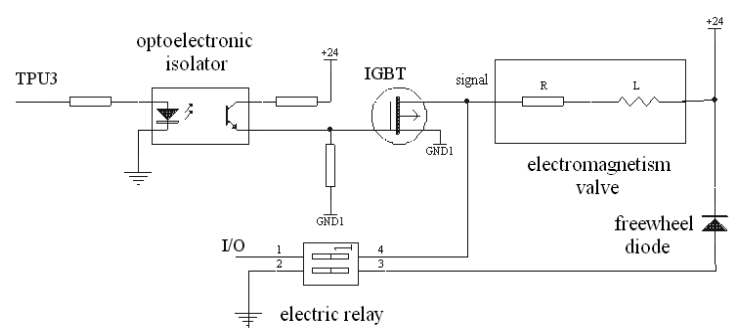

Fig. 4 The principle chart of drive circuit.

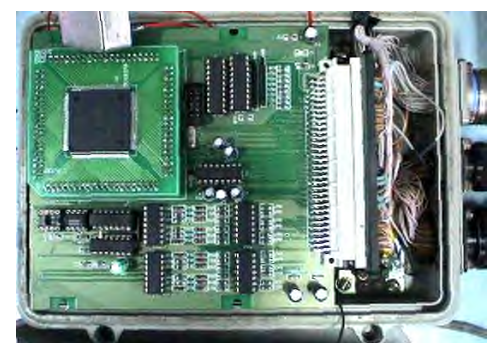

Fig. 5 Picture of ECU.

Commonly, when MOSFET power transistor is used, for the sake of protection of the electromagnetism valve drive level, the method of parallel diode is used to limit the back EMF impact produced when the valve closes off. This method often slows down the speed of current damping, and increases the time of valve closing, which is very bad low voltage control. But IGBT power tube has a voltage regulator protecting circuit so that it can withstand a voltage not exceeding $425 \mathrm{~V}$, which work in the low-frequency electromagnetic valve without external protection, and turn-off time is shorter. However, when electromagnetic valve enters into high-frequency work phase, another free-wheel diode is needed to enhance efficiency. Through optoelectronic isolator, the driving signal will enter into the circuit shown in Fig. 5. Obviously, there exists contradiction in the design of hardware circuit. To resolve it, solid state relays plus IGBT power tube are apply together, for the conversion between high and low frequency control, which is to say, for high-frequency, free-wheeling diode combines with electric relay; for low frequency, the relay separates and parallel diode open.

Test Analysis. This paper takes HD4070PR automatic transmission as an example to analyze the quality of the lockup process. (See Fig. 6)

From the above analysis, self-adoptive control strategy needs to be adopted. Fig. 7 and Fig. 8 are the testing devices and system on board. Fig. 9 is the test result. First of all, some initial values need to be set for the process of oil-filling, open circuit and closed circuit, and save them into EEPROM. The test inspects oil pressure, engine rotating speed, turbine rotating speed, throttle angle, oil temperature and the output shaft torque, and conducts real-time correction to duty ratio of the electromagnetism valve, then save the modified values to EEPROM., for next control on the electromagnetism valve. After several on-line modifications, excellent control results will be achieved. In Fig. 9, the arrows reflect the tendency of the change of self-adoptive controlling process. This figure shows that through correcting related parameters, the disturbance from the output shaft torque has been significantly reduced.

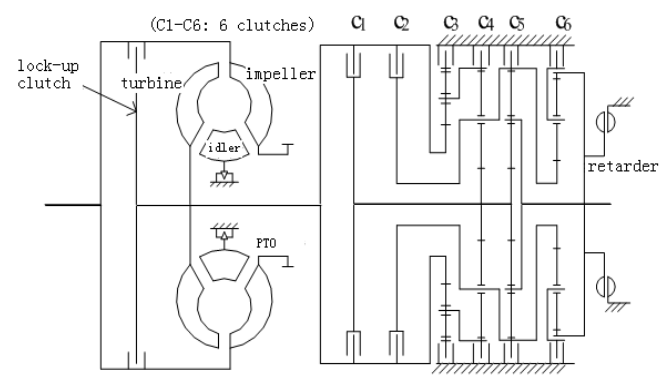

Fig. 6 HD4070PR automatic transmission.

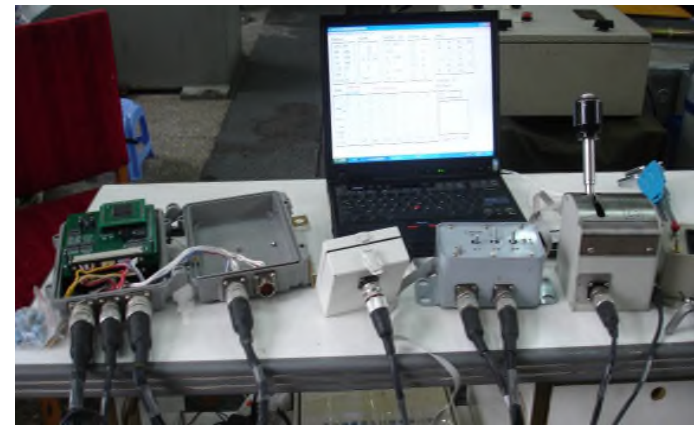

Fig. 7 Testing devices. 


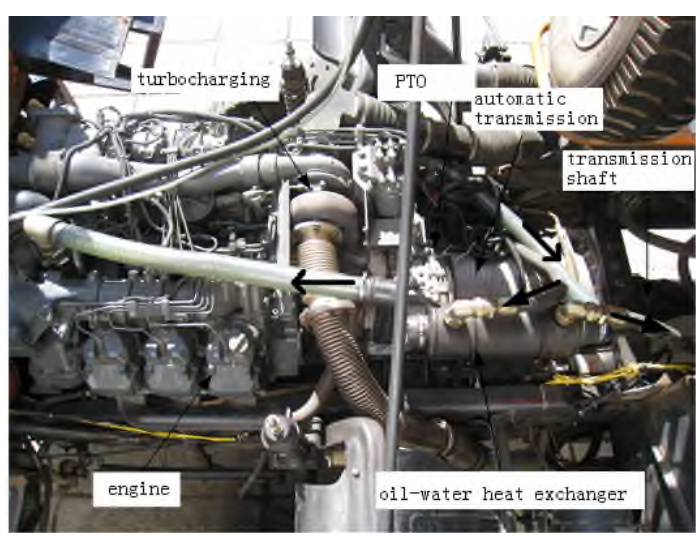

Fig. 8 Systems on board.

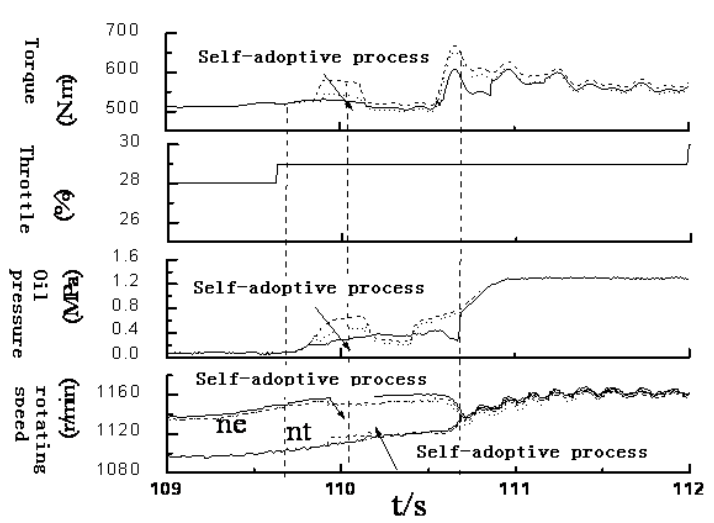

Fig. 9 The self-adoptive control in the lockup process.

\section{Summary}

From the theoretical analysis on the lockup process of torque converter, the author concluded the variation curves, illustrated the necessity of self-adoptive control strategy. Finally, through tests, the author verified the correctness of using self-adoptive control. In conclusion, self-adoptive controlling strategy can enhance quality of the lockup process, achieving an excellent controlling effect.

\section{References}

[1] H. Joachim, B. Joachim, M. Peter, P. Stephan, Flatness-based Clutch Control for Automated Manual Transmissions. Contr. Eng. Pract. 11 (2003) 1353-1359.

[2] K. B. Harmon, The History of Allison Automatic Transmission for On-Highway Trucks and Buses. SAE paper 982791 .

[3] S. Waterchagit, Modeling and Estimation for Speed Automatic Transmission with Clutch-to-Clutch Shift Technology, The Ohio State University, 2003.

[4] S. J. Han, P. Yeong, L. Jang, A Study on the Improvement of the Shift Characteristics for the Passenger Car Automatic Transmission. Int. J. Vehicle Des. 3/4 (2000) 307-328.

[5] B. H. Cho, J. S. Oh, W. H. Lee, Modeling of pulse width modulation pressure control system for automatic transmission. SAE Paper 200220121257, 2002. 